\title{
Exploring the association between occupational complexity and numeracy
}

\author{
Mary Genevieve Billington and Njål Foldnes ${ }^{*}$ (D)
}

*Correspondence: njal.foldnes@gmail.com University of Stavanger, Stavanger, Norway

\begin{abstract}
The basic cognitive skill of numeracy is a recognized form of human capital, associated with economic and social well being for individuals and for nations. In this study, we explore how occupational complexity relates to proficiency in numeracy, among adults in full-time employment. We operationalize occupational complexity by constructing three measures of task complexity: complexity with data, complexity with people and complexity with things. Data from the international OECD survey of adult skills, 2012, is employed to investigate both the distribution of these three dimensions of occupational task complexity and how these relate to numeracy in 13 countries. The analysis indicates that data occupational complexity predicts numeracy scores, when controlling for age, gender and educational level. The findings open for a hypothesis that occupational activities may enhance basic skills in adult populations. If elaborated and supported through further studies this finding has practical implications for workplace organization and contributes to theoretical understandings of the development of basic skills in adults.
\end{abstract}

Keywords: Human capital theory, Numeracy, Skills, Occupational complexity

\section{Introduction}

The notion of human capital refers to knowledge, skills, abilities and other characteristics possessed by individuals which contribute to the wellbeing of the individual, the labour organization and the society more generally (Kwon, 2009). Becker (2009) distinguishes between general and specific human capital. General human capital refers to generic knowledge and skills, such as numeracy, acquired through education and experience, while specific human capital refers to knowledge specific to a firm or task and is rarely transferable. Issues related to both the measurement and development of this capital are relevant in a wide range of disciplines (Della Torre et al., 2018). The Organization for Economic Cooperation and Development (OECD) utilizes international surveys to measure, compare and identify trends in stocks of general human capital across countries.

In this study we investigate mechanisms that may work to maintain and improve numeracy skills, a form of general human capital, in the working population. We go

(c) The Author(s), 2021. Open Access This article is licensed under a Creative Commons Attribution 4.0 International License, which permits use, sharing, adaptation, distribution and reproduction in any medium or format, as long as you give appropriate credit to the original author(s) and the source, provide a link to the Creative Commons licence, and indicate if changes were made. The images or other third party material in this article are included in the article's Creative Commons licence, unless indicated otherwise in a credit line to the material. If material is not included in the article's Creative Commons licence and your intended use is not permitted by statutory regulation or exceeds the permitted use, you will need to obtain permission directly from the copyright holder. To view a copy of this licence, visit http:// creativecommons.org/licenses/by/4.0/. 
beyond the usual unmalleable predictors of gender, age, and initial formal education, that are often used to explain variation in numeracy. Our focus is rather on the complexity of tasks that workers are engaged in and how measures of complexity might relate to numeracy. Occupational complexity is seen in the literature as having three dimensions, relating to data, people and things (Finkel et al., 2009). Figure 1 depicts a simplified model of numeracy as investigated in this study, with the established, unmalleable predictors shown on the left-hand side, and the occupational complexity dimensions shown on the right-hand side.

Theoretical support for the investigation is found in practice engagement theory (Reder et al., 2020) which suggests that engaging in literacy and numeracy activities develops and enforces the cognitive skills required for these same activities and in the intellectual challenge hypothesis (Staff et al., 2004) which proposes that cognitive skills like muscles are developed through use (Baldivia et al., 2008; de Grip et al., 2007; Potter et al., 2007). We choose to empirically investigate the associations between occupational complexity and numeracy.

In this study we use data from the OECD Programme for the International Assessment of Adult Competencies (PIAAC), conducted in 22 countries in 2012. The survey established a comprehensive data base. Three key information-processing skills, literacy, numeracy (termed quantitative literacy in previous OECD studies) and problem solving in a technological environment were measured through testing. This test data was supplemented with data on gender, age, employment and education and data from additional questionnaires, administered via interview (OECD, 2013a, b). The PIAAC survey represents a unique data base. The demonstrated and reported capabilities of adults may be linked to a wide range of attributes and other factors, providing insight into structural relationships and allowing the investigation of mechanisms that may influence skill proficiency (Clair, 2012; Schleicher, 2008; Tighe et al., 2013). To the best of our knowledge, no other studies have investigated the association between numeracy and occupational complexity using the PIAAC data.

The idea that occupational activity may have an effect on cognitive processes and performance is not new but there is a lack of empirical evidence to support the claim (Marquié et al., 2010). We lack understanding of how basic skills are created and maintained beyond initial education and how these skills affect labour market performance for individuals and moreover the general economic activity (Cascio et al., 2008), and the role of basic skills in the labour market remains relatively understudied (Vignoles et al., 2011). Our research aim is to explore how the construct of occupational complexity is related to proficiency in numeracy. The main research question is: How does occupational complexity relate to numeracy scores for adults in full-time employment?

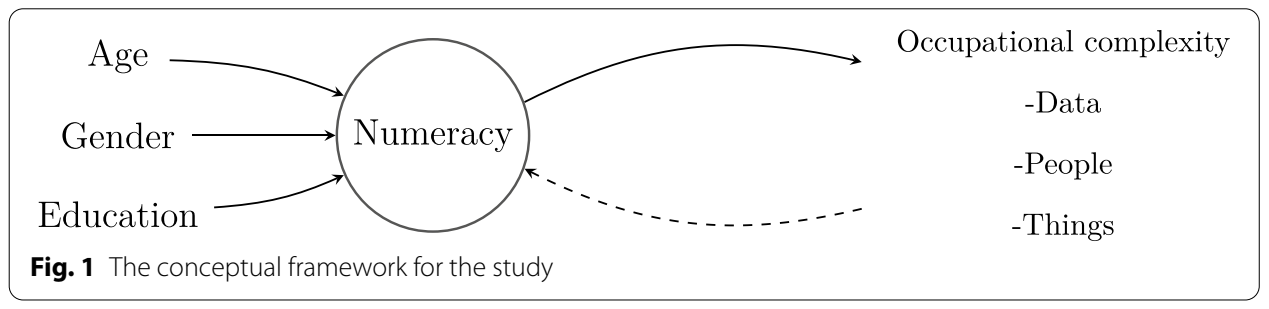


To answer the question we firstly extend the PIAAC data by recoding the existing occupational codes into three new measures of occupational complexity relating to data, people and things.

We then use the new occupational complexity measures in detailed analysis and modeling of numeracy.

Clearly, as in all observational cross-sectional studies, causality cannot be inferred from the findings. The tentative analysis presented in this article represents a first attempt to investigate how occupational complexity may maintain and improve numeracy, over and above the self-selection of people with certain skills into certain jobs. If supported through further research this hypothesis has potential to contribute to understandings of human capital as a dynamic entity which may be maintained and improved through work tasks.

\section{Main notions}

\section{Numeracy}

In the OECD context numeracy is seen as an individual cognitive skill and defined as: ".... the ability to access, use, interpret and communicate mathematical information and ideas, in order to engage in and manage the mathematical demands of a range of situations in adult life" (OECD, 2013a). As such, numeracy extends beyond the mastery of simple arithmetic operations. For the individual, numeracy is the ability to meet effectively the mathematical demands of life (Bennison, 2015).

Numeracy is a transversal skill, which allows people to continue learning throughout their lives.

We choose to investigate the skill of numeracy rather than literacy arguing that the numeracy skill is more powerful. In general, there is a high correlation between literacy and numeracy scores in international test data. In the PIAAC survey, the overall correlation between the two dimensions is 0.87 (Desjardins et al., 2013, p. 85) with little variation between countries, suggesting that for individuals these skills are closely related. However, in the PIAAC survey, a larger proportion of adults perform at the lowest levels of proficiency in numeracy (19.0\%) than in literacy (15.7\%) (Desjardins et al., 2013).

In addition, men and women differ substantially in the numeracy dimension, with women scoring around 13 points below men on average across countries. Longitudinal studies also suggest that numeracy proficiency matters more than literacy proficiency for both economic and social outcomes for individuals Parsons and Bynner (2005).

Links between both proficiency in numeracy and literacy and national economic growth and welfare have been established (Burns et al., 2016; Hanushek and Zhang, 2006; Vignoles et al., 2011; Willms and Murray, 2007). Proficiency in the basic skills of numeracy and literacy predicts employment (Coulombe and Tremblay, 2009). Interestingly, the importance of basic skill proficiency, relative to education qualifications, increases with age with proficiency in basic skills being a better predictor of employment than education level (Burns et al., 2016). Other studies link poor basic skills to increasing health care costs (Greenberg, 2013; Jenks, 1992).

On the individual level, proficiency in numeracy is found empowering and profitable enhancing autonomy and self-determination (Geiger et al., 2015). Adults demonstrating a high proficiency in numeracy are much more likely to be in good health, to be 
employed, to have higher earnings and to take part in community life (Garcia-Retamero et al., 2015; Parsons and Bynner, 1997, 1999, 2005; Tout, 2014). Conversely, lower skilled adults are more likely to have lower earnings (Tighe et al., 2013), to be unemployed, and to leave the workforce earlier (Burns et al., 2016). The negative effects of poor numeracy skills are exaggerated for women (McIntosh and Vignoles, 2001; Reder and Bynner, 2008).

\section{Employment and numeracy}

This study investigates the relationship between proficiency in numeracy and occupational complexity. Previous studies have neglected this work activity differential, assuming that it plays a limited role in skill development (Hanushek and Zhang, 2006), but we claim that there is both statistical and theoretical support to warrant investigation. While initial education is the strongest single factor predicting skill proficiency, earlier studies do indicate a tentative relationship between skill proficiency and occupational activity.

The usual observable pattern in international adult survey data is that numeracy and literacy scores peak in the age group around 30 years and then decline for older age groups, first gradually and then more swiftly. However further exploring data sets shows that this is not the case for all adults (Billington et al., 2017). Employment, for example, has been found to influence an individual's numeracy skill (Fujishiro et al., 2019). The performance gap between the genders increases in the favour of men after initial education also suggesting that types of employment may influence development. In a cross-country analysis of data from a previous adult skills survey, Desjardins (2003) found evidence that type of work and skill related habits could compensate for low levels of education. A later study by Willms and Murray (2007) confirmed that employment has a positive effect on basic skills. These authors suggest that certain occupations and certain firms create a culture that supports and values skills. Nurturing contexts have been found to have significant impact on cognitive development over time (Cascio et al., 2008). Employees who benefit from structural changes in workplace organization, such as promotion, increased responsibility or assignment to non-routine tasks, improve their scores on literacy assessments (Evans et al., 2011, p. 361). Conversely, earlier analysis of OECD surveys (Edin and Gustavsson, 2008) found statistically strong evidence that time out of work equals loss of skill.

\section{Occupational complexity}

In this study, we operationalise the notion of occupational complexity, previously used in smaller studies related to cognitive functioning. Occupational complexity refers to the complexity of the occupational tasks required of a worker. Occupational complexity, so defined, has three dimensions, coined as data, people and things (Finkel et al., 2009). Different variables are employed to measure the level of complexity at which a worker functions in relation to each of the three dimensions (England and Kilbourne, 1988). High data complexity tasks require complex analysis of data, in the form of information, knowledge or concepts. High people complexity tasks are characterized by complex social skills such as those practiced by psychologists, lawyers, teachers and social workers. High things complexity tasks entail precision work, such as that required of a 
watchmaker or toolmaker. Studying the distribution of occupational complexity, Greene (2013) found that men consistently reported having more complex jobs than women, most significantly in the data and things dimensions.

The basic proposition is that exposure to complex environments at work facilitates cognitive functioning (Finkel et al., 2009). Greene (2013) reported that working with people, through teamwork and supervisory capacities had a formidable influence on cognitive health, independent of education and intellect.

Studies considering the relationship of occupational complexity to cognitive ageing tend to confirm the hypothesis that both complex work and non-routine work support stable cognitive function. Exposure to stimulating environments in the work situation reduces the expected effects of ageing on cognitive abilities (Feldberg et al., 2014; Finkel et al., 2009; Smart et al., 2014; Valdés et al., 2014). Andel et al. (2014) looked at the influence of mid-life complexity tasks, in both occupation and leisure, on cognitive functioning in older years and found a positive correlation between occupational complexity in both the data and people dimensions and late-life cognitive scores. Andel et al. (2005) found that complexity of work with people was most significant in reducing the risk for dementia when taking age, gender, and level of education into account.

\section{Method}

Data

The data used in this study stem from the OECD survey of Adult Skills, PIAAC, conducted in 22 OECD countries in the period 2011-2012 (OECD, 2013a). Approximately 5000 adults in the age group 16-65 years participated in the survey in each country. To maximize comparability, all countries met stringent standards relating to the target population, sample design, sample selection response rates, and non-response bias analysis. Participating countries were required to use a probability sample representative of the target population. Detailed information regarding sample designs can be found in the Technical Report of the Survey of Adult Skills (OECD, 2013b). Data for all countries except Australia are freely accessible from the OECD PIAAC website.

When working with international assessment data, the calculation of mean statistics, standard errors and regression estimates should take into account the complex sample design, including replicate weights and the use of rotated test forms. Rotated test forms are handled statistically by using plausible values. For PIAAC these are 10 values for each individual that contain information of the numeracy proficiency of that individual. The location and spread of the plausible values reflect the proficiency level and its degree of uncertainty. Variance estimates are obtained using jackknife replicates associated with the weights. In the present study, proper statistical handling of PIAAC data, based on plausible values and sampling weights, was provided by the R (R Core Team, 2020) package EdSurvey (Bailey et al., 2021). For further information about the technical details of PIAAC data handling using EdSurvey, see Bailey et al. (2020).

\section{Sample investigated}

Thirteen of the 22 countries in the PIAAC study employed the current International Standard Classification of Occupations (ISCO), version 08, of the International Labour Organization. This variable was necessary to code occupational complexity (detailed 
later). Data from these 13 countries were selected for analysis. The countries (see Table 1) display wide geographical, demographic and economic variation. Foreign-born adults were excluded from the country samples. As the OECD survey is administered in the official language/s of the participating country, it is unclear if the test measures proficiency in second language and/or proficiency in basic skills for foreign-born participants.

In addition, as a large proportion of the 16-24 year age group is engaged in formal schooling, we followed earlier studies (Cascio et al., 2008; Desjardins, 2003; Desjardins and Rubenson, 2013; Hanushek and Zhang, 2006) and omitted participants in this age range from the samples. Further, in the PIAAC coding system respondents coded as part-time employment included persons engaged in any paid employment, regardless of the number of hours employed, thus making comparisons difficult. We therefore decided to include only full-time employees in our samples. The resulting number of adults in our sample, across these 13 countries, was 33,765. We further excluded those adults registered in the data without valid current occupation ISCO-08 codes. The final sample consisted of 33,054 native-born full-time employees in the age range 25-65 years in 13 countries. Table 1 gives the gender frequencies in each country, with associated mean numeracy levels.

It is noteworthy that missing data are rare when working with high-quality large-scale datasets such as PIAAC. For most variables used in the analyses, there was no missing data. However, the variable measuring years of education contained a small amount of missing data (less than 1\%).

\section{Measures}

Measures of age, gender, years of education, and the ISCO-08 occupation code were obtained directly for each individual from the PIAAC data set. The variables of age, gender and years of education served as control variables in the regression models. Age was categorized into 10-year intervals, from age 25 with the last interval 55-65, being of 11 years. For some descriptive graphs, years of education was collapsed into three

Table 1 Number of men and women in each country sample, with associated mean numeracy scores $\bar{x}$. Source: PIAAC 2012

\begin{tabular}{lcccc}
\hline Country & Men N & Women N & Men $\overline{\boldsymbol{x}}$ & Women $\overline{\boldsymbol{x}}$ \\
\hline Belgium & 1316 & 752 & 299.0 & 289.8 \\
Czech Republic & 1369 & 1166 & 285.6 & 276.9 \\
Denmark & 1764 & 1244 & 298.6 & 287.5 \\
France & 1737 & 725 & 272.5 & 265.3 \\
Italy & 1211 & 841 & 261.5 & 259.2 \\
Japan & 1704 & 1271 & 300.1 & 291.9 \\
Korea & 2062 & 391 & 269.8 & 258.7 \\
Netherlands & 1342 & 1204 & 298.7 & 286.3 \\
Norway & 1200 & 1219 & 302.0 & 289.1 \\
Poland & 1540 & 848 & 269.0 & 267.6 \\
Slovak Republic & 1440 & 1480 & 287.5 & 286.4 \\
Spain & 1328 & & 267.0 & 255.7 \\
United Kingdom & 1840 & 280.6 & 270.5 \\
\hline
\end{tabular}


educational levels: lower secondary or below, upper secondary or equivalent, and degree or above. Summary statistics for years of education, together with percentage proportions for educational level, age groups, and gender are given in Table 2.

The ISCO-08 code is a four-digit categorization created by the International Labour Organisation to allow for comparison of occupations between countries. The first digit signifies one of 10 major occupational groups, thereafter the second digit signifies 43 sub-major groups, the third digit signifies 130 minor groups and the fourth digit signifies 436 unit groups. In general, countries coded the PIAAC data at the three-digit level. Categorization at the unit level would presumably have resulted in groups, which are too small to allow for comparisons. For each occupational title, the ISCO-08 handbook International standard classification of occupations (2010) provides a thorough description of the activities of the occupation.

The following procedure was employed in order to map the ISCO codes in the data onto the three dimensions of occupational complexity: people, data and things. The occupational descriptions in the ISCO handbook were matched to a complexity index obtained from the Dictionary of occupational titles (2016) (DOT) to assign three occupational complexity measures to each occupation ISCO code. The DOT complexity index defines further levels of complexity within each dimension; each level is described with associated characteristics. There are seven levels of data complexity, nine levels of complexity with people and seven levels of complexity with things, listed in Table 7 in Appendix 1. Each DOT level is given a name, e.g., the highest data complexity level is called 'Synthesizing, whose meaning is further described in the DOT manual. The procedure to create a crosswalk between ISCO codes and DOT codes, and the subsequent complexity assignment, may be described as follows:

1. Two researchers independently and carefully read the ISCO description for each ISCO code. Then, for each complexity dimension, each researcher identified the DOT level that best reflected the information given in the ISCO description.

2. The assigned levels were compared among the two researchers. In the case of discrepancy in assigned levels, the final DOT complexity level was identified through

Table 2 Summary statistics for covariates. Source: PIAAC 2012

\begin{tabular}{lrllllll}
\hline Variable & N & \% missing & Mean & Std. Dev. & Min & Median & Max \\
\hline Years of education & 32,783 & 0.8 & 13.462 & 2.914 & 4 & 16 & 22 \\
Educational level & 33,054 & 0 & & & & & \\
Lower secondary & 4317 & & $13.1 \%$ & & & \\
Upper secondary & 14,757 & & $44.6 \%$ & & & \\
Degree & 13,980 & & $42.3 \%$ & & & \\
Age groups & 33,054 & 0 & & & & \\
25-34 & 8543 & & $25.8 \%$ & & \\
$35-44$ & 9449 & & $28.6 \%$ & & \\
$45-54$ & 9284 & & $28.1 \%$ & & & \\
55 plus & 5778 & & $17.5 \%$ & & & \\
Gender & 33,054 & 0 & & & & \\
Male & 19,853 & & $60.1 \%$ & & & \\
Female & 13,201 & & $39.9 \%$ & & & \\
\hline
\end{tabular}


discussion among the researchers. The final complexity level was then produced by collapsing the more fine-grained DOT levels into a three-level scale of low, moderate, and high complexity.

The results of this procedure are available in Table 8 in Appendix 1. The coding in Step 1 was controlled for inter-rater reliability (Bryman, 2015) and was deemed adequate (87\%). The mapping of complexity scales in Step 2 is given in Table 7 in Appendix 1. We note that the above procedure is transparent and may be replicated. To the best of our knowledge, the procedure is new in the literature. We believe that the new mapping of ISCO codes to complexity levels made available in Table 8 may be of benefit in future research that draws upon large-scale international data to investigate occupational complexity.

We illustrate the procedure with an example. The ISCO-08 occupation code 213 represents the minor group: life science professionals. By reading the ISCO description of this occupational group, the researchers identified the highest level ' 0 : Synthesizing' on the DOT data complexity scale, as the work entails synthesizing data. On the DOT people complexity scale, the level '3: Supervising' was identified, as the work involves supervising others. As for things complexity, the DOT level '1: Precision' was identified, as the occupation involves precision working. These DOT levels where then mapped to the more coarse scale of high, moderate and high complexity with data, people and things, respectively. In Appendix 3 we further investigate our new occupational complexity measures with respect to construct validity.

\section{Analysis}

We firstly analyze the distribution of the three constructed complexity measures, within each country and in the total sample. Secondly, covariation among pairs of complexity types was investigated before proceeding to relate occupational complexity to numeracy scores, first by means of simple summary statistics and graphs for each of the 13 countries. Finally, the following regression model was used to control for important background variables while looking at the relation of complexity to numeracy.

$$
\begin{aligned}
\text { Num }= & \beta_{0}+\beta_{d}^{\text {Mod }} D_{d}^{\text {Mod }}+\beta_{d}^{\text {High }} D_{d}^{\text {High }}+\beta_{p}^{\text {Mod }} D_{p}^{\text {Mod }} \\
& +\beta_{p}^{\text {High }} D_{p}^{\text {High }}+\beta_{t}^{\text {Mod }} D_{t}^{\text {Mod }}+\beta_{t}^{\text {High }} D_{t}^{\text {High }}+\beta_{X} X+\delta,
\end{aligned}
$$

where Num refers to an individual's numeracy score, while $D_{d}^{\text {Mod }}$ and $D_{d}^{\text {High }}$ are dummy variables corresponding respectively to moderate and high data complexity, so that low data complexity serves as reference category. Likewise, $D_{p}^{\text {Mod }}$ and $D_{p}^{\text {High }}$ are dummy variables for moderate and high people complexity, respectively, while $D_{t}^{\text {Mod }}$ and $D_{t}^{\text {High }}$ are dummy variables corresponding to moderate and high things complexity. Individual background variables are age group, years of education and gender. These are included in the vector $X$. In order to achieve valid inference for the regression parameters the sampling design of PIAAC was taken into account, through the use of sampling weights and proper handling of plausible values. Missing data are very rare in the PIAAC sample, and the exclusion of cases with missing data should therefore not bias our results. In each analysis, we therefore removed cases with missing data. 
Table 3 Percentages and mean numeracy scores for each occupational complexity level, for each dimension. Source: PIAAC 2012, DOT index, ISCO-08 codes

\begin{tabular}{llll}
\hline Complexity type & Complexity level & Percentage & Mean numeracy (SE) \\
\hline Data & Low & 30.5 & $260.5(0.8)$ \\
& Moderate & 50.2 & $282.3(0.6)$ \\
People & High & 19.3 & $298.5(1.0)$ \\
& Low & 56.0 & $270.6(0.6)$ \\
& Moderate & 22.4 & $286.4(1.0)$ \\
Things & High & 21.6 & $289.5(1.0)$ \\
& Low & 59.7 & $283.6(0.5)$ \\
& Moderate & 25.4 & $265.2(0.8)$ \\
\hline
\end{tabular}

SE standard error

Table 4 Polychoric correlations among the three types of complexity in total sample. Source: PIAAC 2012, DOT index, ISCO-08 codes

\begin{tabular}{llll}
\hline & Data complexity & People complexity & $\begin{array}{l}\text { Things } \\
\text { complexity }\end{array}$ \\
\hline Data complexity & 1 & & \\
People complexity & 0.569 & 1 & 1 \\
Things complexity & -0.084 & -0.319 & \\
\hline
\end{tabular}

\section{Findings}

\section{Occurrence and covariation of occupational complexity}

Following the procedure detailed, Table 3 shows the proportions of the sample associated with each level of complexity for the total data. The three dimensions are distributed differently. Within each dimension of complexity, the smallest proportion of respondents, between $15 \%$ and $22 \%$, have occupations with a high level of complexity. The distribution of data complexity is rather symmetric and centered, with half of the employees having moderate complexity with data. In both the people and the things dimensions, the distribution is skewed, with the highest proportion, 50-60\%, of respondents in occupations with low complexity. In regards to the people dimension, one interpretation is that a large proportion of respondents have jobs with a work organization that entails little responsibility towards others.

Next, we consider in Table 4 the associations among the complexity types in the total sample, using polychoric correlations (Foldnes and Grønneberg, 2020). These are correlations suitable for investigating the associations among ordinal-level variables. The strongest association is positive, and relates data and people complexity. That is, for individuals in occupations coded with high data complexity, the same occupation tends to be coded with high people complexity. There is no clear correlation between having an occupation with high data complexity and the same occupation having high things complexity. There is a moderate negative correlation between having an occupation with high things complexity and the same occupation having high people complexity. For more refined results concerning the bivariate distributions of complexity levels within each country the reader is referred to Appendix 2, Fig. 6. 


\section{Numeracy and occupational complexity}

We now turn to the main focus in the present study, namely the relation between numeracy and occupational complexity as illustrated in Fig. 1. Columns 4 and 5 in the Table 3 show the mean numeracy scores, with associated standard errors, for each complexity level within the three complexity dimensions. In both the data and people dimensions, higher levels of occupational complexity are clearly associated with higher numeracy scores, and this effect appears substantial. In the data dimension, we observe a 38-point difference in numeracy score, between low and high complexity, while in the people dimension, the difference is 19 points. This is not the case for complexity with things. The group of individuals in occupations with low things complexity had the highest numeracy scores.

We calculated the effect sizes across complexity levels for each complexity dimension, see Table 5.

As a rule-of-thumb, effect sizes $d$, are classified as small if $d=0.2$, medium if $d=0.5$ and large if $d>0.8$ respectively (Cohen, 1988). In the data dimension, the large effect size $(d=0.82)$ indicates a large difference in numeracy scores between employees in occupations with high data complexity, compared to employees in occupations with low data complexity. Similarly, in the people dimension, we find medium to large effect sizes $(d=0.5)$ with respect to numeracy performance between those in occupations with high complexity and those in occupations with low complexity. In the complexity with things dimension, when comparing numeracy scores for individuals in occupations with moderate things complexity to the low things complexity the effect size is medium and negative.

\section{Numeracy and occupational complexity within educational levels and countries}

The relation between each complexity measure and numeracy is next investigated for each country within each education level.

Considering the data dimension, Fig. 2 shows the relation between the complexity levels to numeracy scores, in each country. Mean scores and standard errors were calculated for each country separately, and error bars corresponding to $95 \%$ confidence intervals for the means are shown. In all countries, we observe that numeracy scores consistently increase as the educational level increases. Also, keeping the educational level constant, there is a general pattern of increased numeracy with increased data complexity. While the level of overall numeracy scores varies across countries, for

Table 5 Effect size. Source: PIAAC 2012, DOT index, ISCO-08 codes

\begin{tabular}{lllr}
\hline & \multicolumn{2}{l}{ Complexity type } & Things \\
\cline { 2 - 4 } & Data & People & 0.32 \\
High-moderate & 0.35 & 0.17 & -0.07 \\
High-low & 0.82 & 0.50 & -0.39 \\
Moderate-low & 0.46 & 0.33 & \\
\hline
\end{tabular}

Numeracy scores across levels of complexity

Dataoccupational complexity with data, People Occupational complexity with people, Things Occupational complexity with things

High-moderate refers to effect size of mean numeracy between high and moderate levels of complexity 


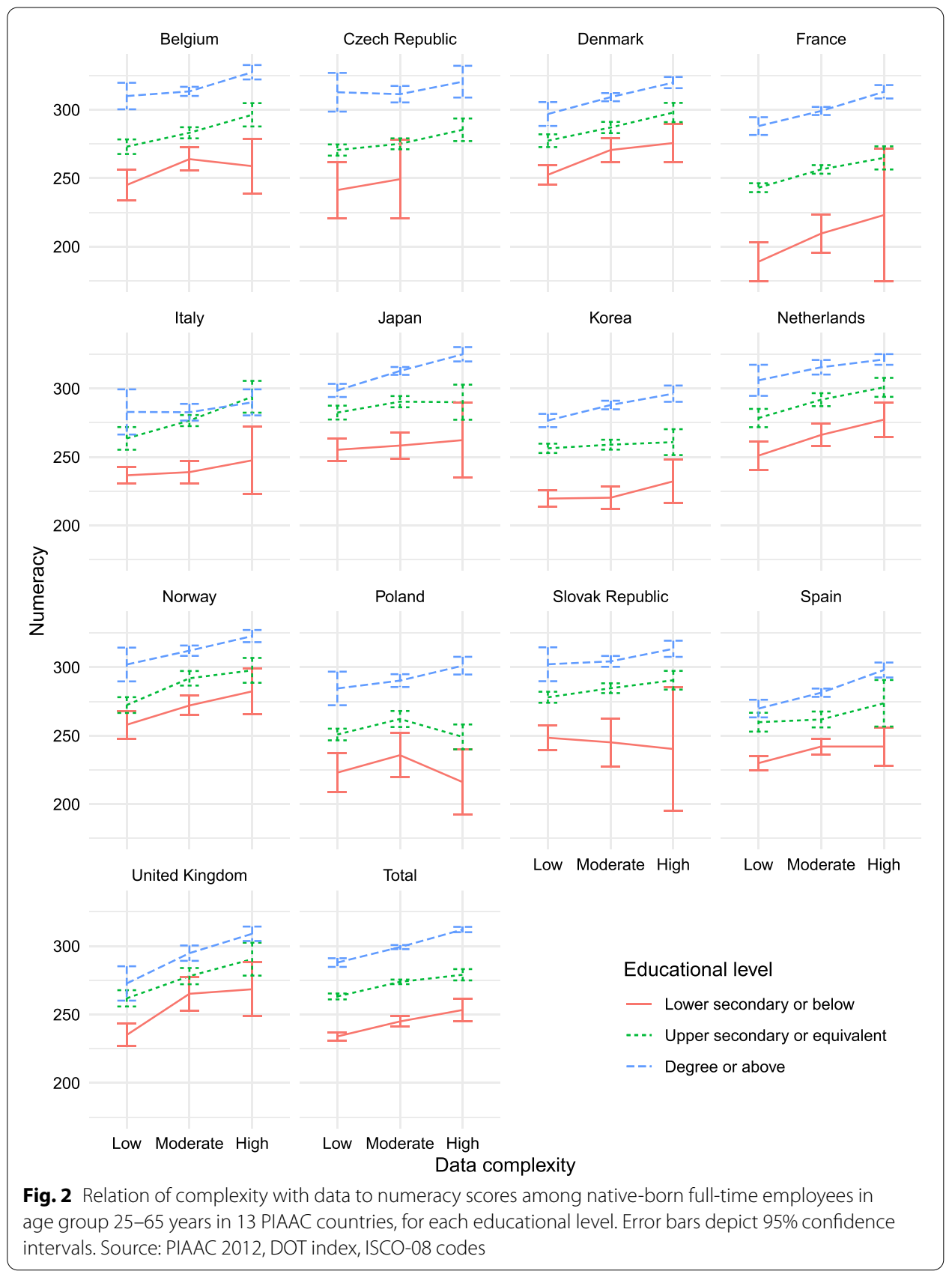

example Japan displays a higher overall numeracy than Korea, we see that the same pattern for the total data (Table 3) is approximately reproduced in every country. Higher levels of data complexity are clearly associated with higher numeracy scores. For the groups with low educational levels, it is harder to read trends, given the low number of participants with the lowest educational attainment (Table 3), yielding high standard errors. In summary, the last panel depicts the numeracy scores for the total sample. It is seen in the total data that higher complexity with data is associated with higher numeracy, within each of the three levels of educational attainment. 
Considering the people dimension, Fig. 3 depicts the relationship of people complexity to numeracy scores in each of the selected countries, and, in the last panel, for the total sample. In contrast to the clear association between numeracy and data complexity, numeracy was only weakly associated with people complexity. In the panel for the total sample, we can see that the aggregated data suggest that for the medium and high levels of educational attainment, there is a weak positive correlation between numeracy and people complexity. For the more sparsely populated level of low educational attainment, the standard errors are large, and no correlation is discernable.

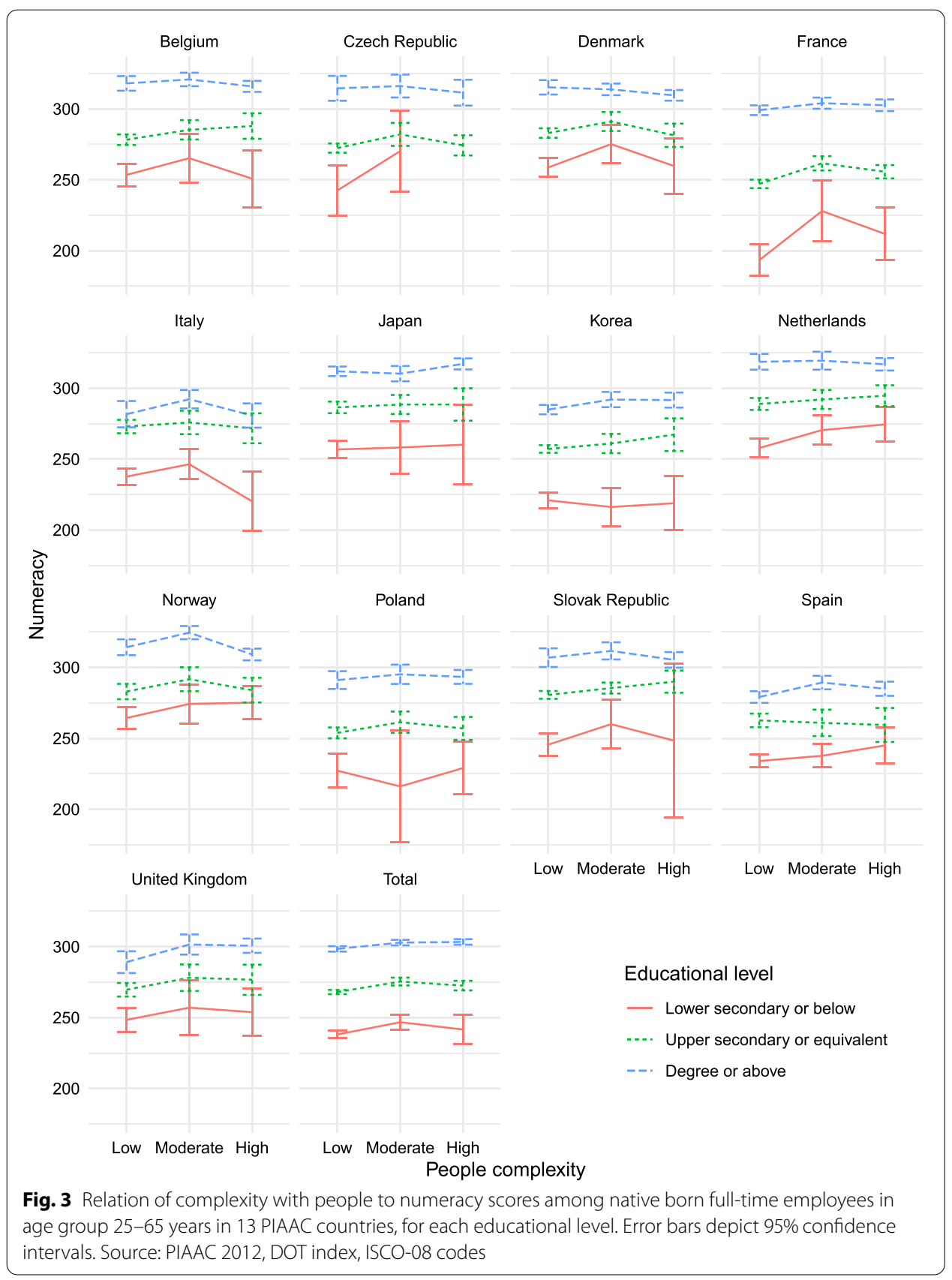


Finally, Fig. 4 depicts the relationships between levels of complexity with things and numeracy scores. In contrast to complexity with data and people, complexity with things has a U-shaped association with numeracy. It is for the moderate complexity level that the lowest numeracy scores occur. In the total sample, this holds true for all three educational levels. One factor that may help explain this, is that things complexity is negatively associated with both data and people complexity (Table 4). Then, the group of low things complexity is associated with higher-than average data and people complexity, and the latter complexity types are in general positively associated with numeracy (Figs. 2 and 3).

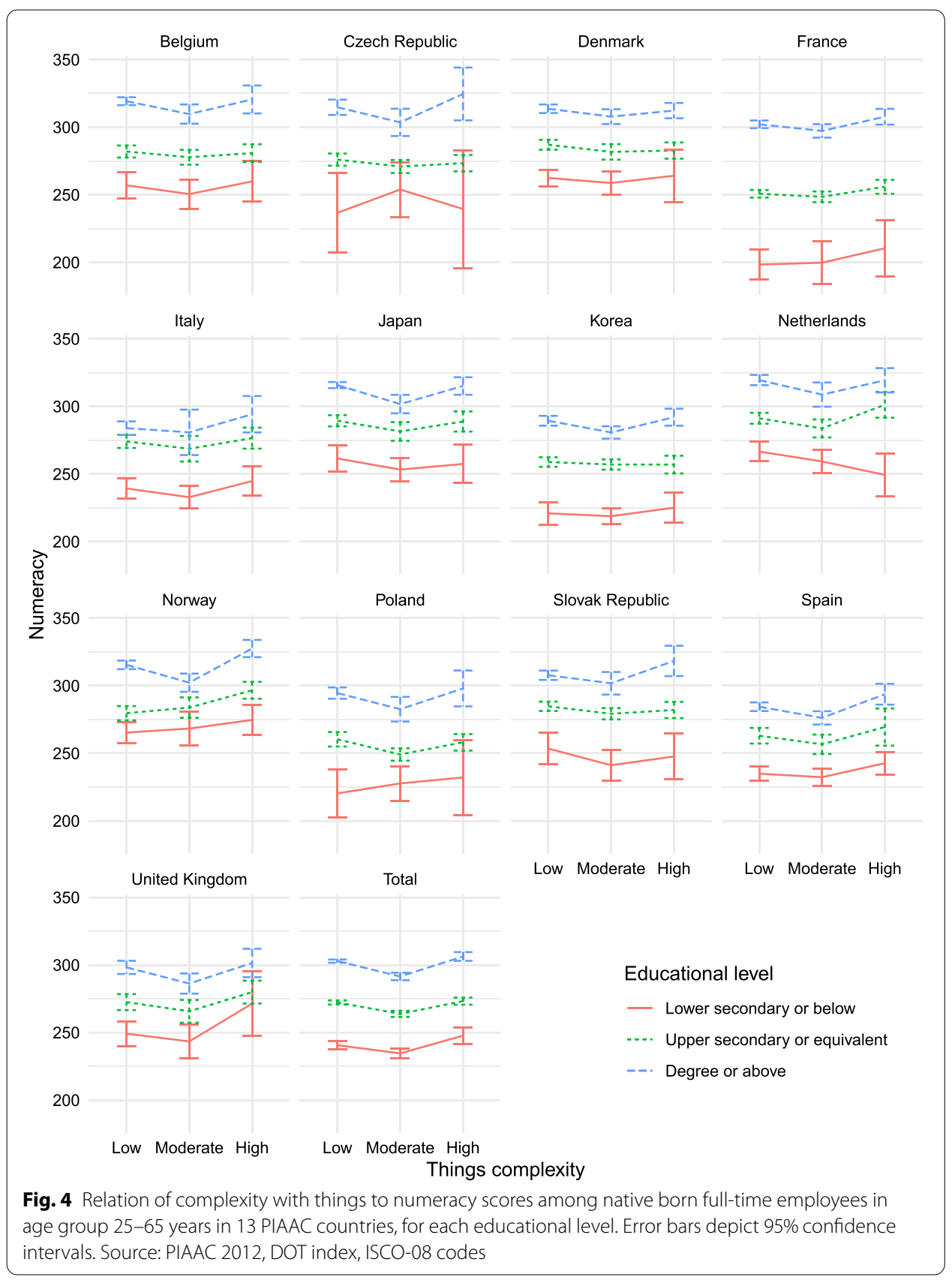




\section{Occupational complexity as a predictor of numeracy, while controlling for education}

We now proceed to estimate the regression coefficients associated with occupational complexity, while controlling for age group, years of education and gender, as specified by Eq. (1). The regression model was estimated independently in each of the 13 countries, with complete tables containing all regression coefficients for each country given in Appendix 4. In Table 6 we report the regression coefficients for the subset of predictors that is the main focus in the present study, namely the complexity measures. For a visual representation of the coefficients, see Fig. 5.

Table 6 and Fig. 5 show that complexity with data is a stronger predictor of numeracy than complexity with people and complexity with things. This finding reflects the observed trends in Figs. 2, 3, 4. High data complexity is associated with higher numeracy than moderate data complexity. The mean regression coefficient values, across countries, associated with moderate and high data complexity were 8.9 and 14.6, respectively. The corresponding mean coefficient values for moderate and high people complexity were 2.4 and -1.0 , respectively. With respect to things complexity, moderate and high complexity had associated mean coefficient values of -5.2 and -1.1 , respectively.

\section{Discussion}

In this study, we present new findings that relate occupational complexity to numeracy in adult working populations across 13 countries participating in PIAAC. The first findings relate to occurrence of the dimensions and levels of occupational complexity in the data set. In all countries, there were greater proportions of adults in jobs with low complexity in both the people and things dimension than in jobs with low complexity in the data dimension. This may well reflect the ongoing digitalization of the workplace, where almost all occupations now involve some use of advanced technology. Between countries, the greatest variations were in the people complexity dimension. Countries with

Table 6 Regressing numeracy on complexity. Source: PIAAC 2012, DOT index, ISCO-08 codes

\begin{tabular}{llllllll}
\hline Country & $\boldsymbol{\beta}_{\boldsymbol{d}}^{\text {Mod }}$ & $\boldsymbol{\beta}_{\boldsymbol{d}}^{\text {High }}$ & $\boldsymbol{\beta}_{\boldsymbol{p}}^{\text {Mod }}$ & $\boldsymbol{\beta}_{\boldsymbol{p}}^{\text {High }}$ & $\boldsymbol{\beta}_{\boldsymbol{t}}^{\text {Mod }}$ & $\boldsymbol{\beta}_{\boldsymbol{t}}^{\text {High }}$ & $\boldsymbol{R}^{\mathbf{2}}$ \\
\hline Belgium & $10.2^{* * *}(2.8)$ & $19.6^{* * *}(3.2)$ & $2.9(2.5)$ & $0.1(2.6)$ & $-4.8^{*}(2.6)$ & $-3.3(3.3)$ & 0.31 \\
Czech Republic & $1.8(2.8)$ & $8(4.7)$ & $1.3(3.4)$ & $-4(4.3)$ & $-4(3)$ & $-2.4(4.3)$ & 0.27 \\
Denmark & $11.7^{* * *}(2.1)$ & $19.2^{* * *}(3)$ & $-0.5(2.4)$ & $-5^{* *}(2.4)$ & $-5.5^{* *}(2.1)$ & $-7.1^{* *}(2.3)$ & 0.27 \\
France & $12.1^{* * *}(1.7)$ & $20.4^{* * *}(2.7)$ & $4.2^{*}(2.2)$ & $1.4(1.9)$ & $-4.3^{* *}(1.8)$ & $-0.6(2.4)$ & 0.37 \\
Italy & $5.7^{*}(3.2)$ & $14^{* * *}(5)$ & $3.5(3.8)$ & $-11^{* *}(4.6)$ & $-8^{* *}(3.7)$ & $-0.3(4.3)$ & 0.23 \\
Japan & $6.7^{* * *}(2)$ & $12.9^{* * *}(3.4)$ & $-2.4(2.3)$ & $-1.1(2.4)$ & $-7^{* * *}(2.4)$ & $-4.8^{*}(2.4)$ & 0.25 \\
Korea & $4.3^{* * *}(1.5)$ & $7.7^{* * *}(2.6)$ & $3.5(2.3)$ & $4.7^{*}(2.6)$ & $-2.9^{*}(1.7)$ & $-3.2(2.6)$ & 0.34 \\
Netherlands & $12.5^{* * *}(3.1)$ & $18.2^{* * *}(3.6)$ & $0.5(2.8)$ & $-0.4(2.8)$ & $-6^{* *}(2.8)$ & $-3.6(3.6)$ & 0.31 \\
Norway & $16.4^{* * *}(2.4)$ & $20.4^{* * *}(3)$ & $8.7^{* * *}(3)$ & $0.3(3)$ & $-1.4(2.7)$ & $7.1^{* *}(3)$ & 0.29 \\
Poland & $6.4^{* *}(2.7)$ & $5.7(3.7)$ & $2.9(3.3)$ & $1.3(2.9)$ & $-10.3^{* * *}(2.8)$ & $-2.8(3.3)$ & 0.22 \\
Slovak Republic & $2.9(2.8)$ & $6.2(3.7)$ & $2(2.2)$ & $-1.9(2.7)$ & $-4.2^{*}(2.4)$ & $-0.3(3.4)$ & 0.17 \\
Spain & $8.1^{* * *}(2.5)$ & $13.4^{* * *}(4)$ & $1.7(2.5)$ & $0.6(2.7)$ & $-5.9^{* * *}(2.1)$ & $2.2(2.5)$ & 0.33 \\
United Kingdom & $16.7^{* * *}(3.2)$ & $24.5^{* * *}(4.3)$ & $2.7(3.6)$ & $2.6(3.5)$ & $-3.8(3.1)$ & $5.4(3.7)$ & 0.2 \\
\hline
\end{tabular}

$\beta_{d}^{\text {Mod }}$ and $\beta_{d}^{\text {High }}$ : estimate of moderate and high data complexity. $\beta_{p}^{\text {Mod }}$ and $\beta_{p}^{\text {High }}$ : estimate of moderate and high people complexity. $\beta_{t}^{\text {Mod }}$ and $\beta_{t}^{\text {High }}$ : estimate of moderate and high things complexity. Reference category is low complexity. Standard errors in parentheses

$*$ * ****** refer to significance at the $.1, .05$, and .01 levels, respectively 


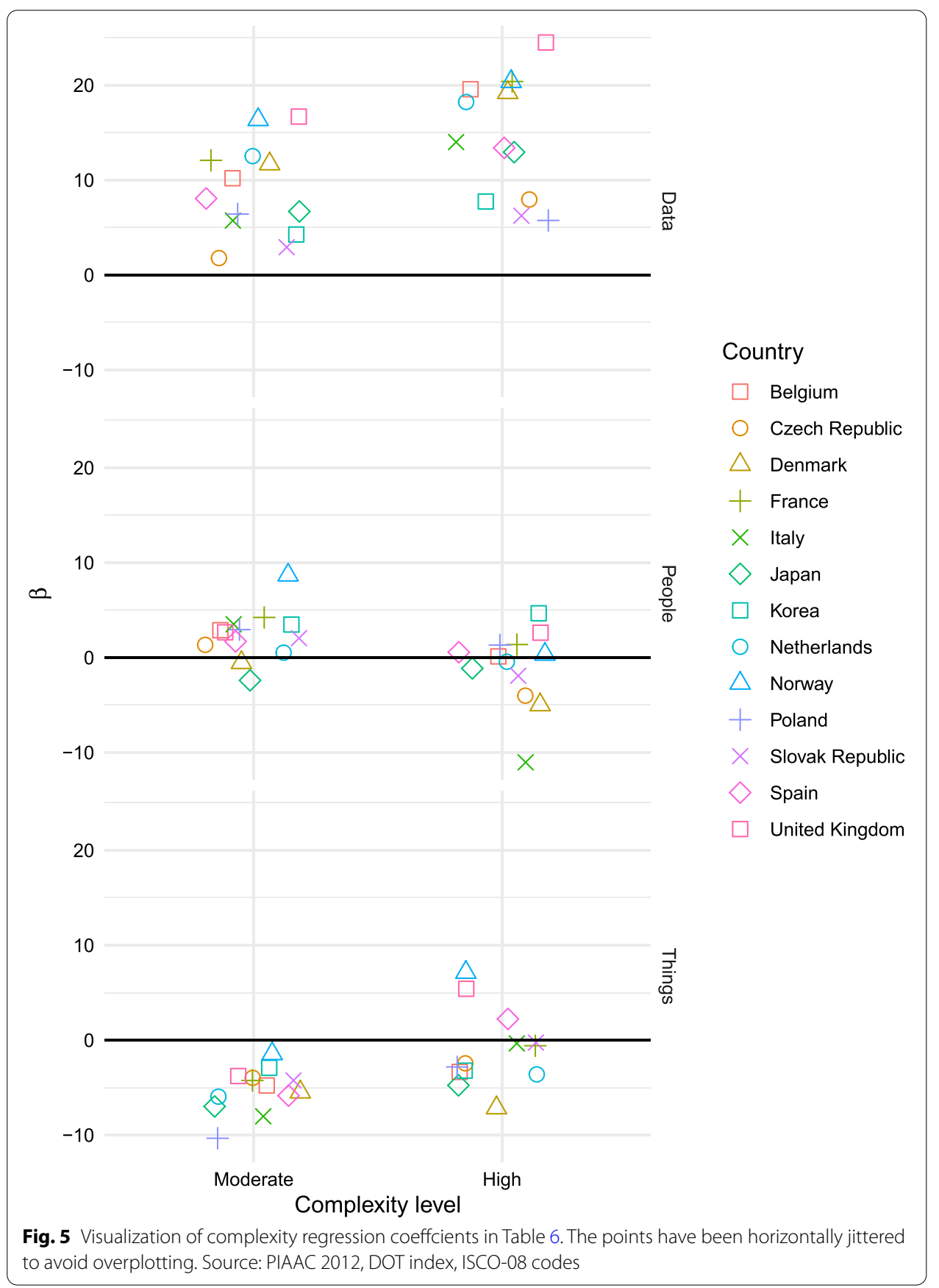

strong social democratic profiles, such as Norway and Denmark had the highest proportion of workers in occupations with moderate or high people complexity. These findings support the construct validity of the new measures. As each occupation is associated with three measures of complexity, we explored how the different dimensions of complexity co-varied in the total sample. High data complexity was associated with high people complexity. Also, high people complexity was associated with low things complexity.

Investigating the association between occupational complexity and numeracy, as illustrated in Fig. 1, without controlling for background variables, we observed a positive 
relationship between both the data and the people dimensions of occupational complexity and numeracy proficiency in the total sample; as complexity increases so do numeracy scores (Table 3). As for occupational things complexity, we found a U-shaped relationship with numeracy.

Considering the country context, and controlling for educational level, all three dimensions behave consistently in all countries (Figs. 2, 3, 4). This invariance implies that the constructed occupational complexity measures relate to numeracy scores in a consistent way across the 13 countries, lending support to the external validity of these measures. This also opens for the use of these measures in analysis of data from countries not included in the present study.

The general relation between complexity and numeracy differs among the three dimensions. In all countries, numeracy scores increase as complexity with data increases (Fig. 2). When controlling for educational level, increasing complexity with people activity was not clearly associated with higher numeracy scores (Fig. 3). For the things dimension, the U-shaped relationship was retained withing educational groups (Fig. 4).

To fully control for background variables of years of education, age and gender, and regression analysis was performed within each country. The results showed, in line with the preliminary investigations described above, that data complexity was a strong predictor for numeracy, even when controlling for education, age, gender and occupational complexity in the people and things domains. All else being equal, the expected change in numeracy between a low and a high complexity occupation had a mean value of almost 15 points on the numeracy scale. To shed some light on this number with a simplified example, let us consider the gender gap in numeracy. When controlling for occupational complexity dimensions, age, and education, the mean gender gap across the 13 countries was 12 points on the numeracy scale. However, all else being equal, if a female has a high data complexity occupation, while a male has a low data complexity occupation, the model predicts that the female will have a higher numeracy score $(15-12=3$ points) than the male. That is, the data complexity dimension appears to compensate for the gender gap. As for the other occupational complexity dimensions, people and things, we did not find such strong associations to numeracy, when controlling for education, gender, age, and data complexity.

Surely, the interaction between numeracy and occupational complexity is complex and involves causal mechanisms in both directions (Fig. 1). The picture may be further obscured by the possibility of hidden and/or confounding variables. Both causal and non-causal explanations may be proposed to explain the findings. A reverse causation argument would be that people choose or are placed in occupational activities compatible with their abilities. This alternative explanation however does not explain changes in skill level between the age groups. Also, we control for education, the main predictor of numeracy (Desjardins et al., 2013), and still find that data complexity strongly predicts numeracy.

A main strength with this study is the use of open access high-quality large-scale international survey data. Measures of numeracy were obtained directly from the PIAAC data and measures of occupational complexity were constructed using a new transparent procedure, taking advantage of the ISCO-08 categorization available in PIAAC. This 
allows for comparison of occupations across nations, and reflects objectively the labour markets in the countries in the study in a nuanced manner.

The resulting mapping of occupational codes to complexity in three domains (Table 8) may be used in future research where ISCO codes are available, and where measures of occupational complexity are of interest. An alternative to this new procedure considered was to use self-reported data from the PIACC interviews to create the same new complexity variables. In the interview, participants responded to a number of questions related to their job activities. We used two of these questions to validate the coding system. A main advantage of this method would be that participants report on their actual activities. Disadvantages are that the data are self-reported, unique to the PIAAC data set, and that the actual coding requires more interpretation.

PIAAC is a large-scale cross-sectional observational study and therefore supplies accurate estimates of associations. However, the causal nature of these associations should be interpreted with caution. Longitudinal studies would provide a better foundation for causal claims. Another avenue for further research would be to investigate the literacy and problem solving domains in PIAAC. Further research could include activities outside of the workplace.

\section{Conclusion}

Basic cognitive skills are a recognized form of human capital contributing to the welfare of individuals and nations alike. This study employed large-scale international survey data (PIAAC) to investigate the relationship between occupational complexity and proficiency in the basic skill of numeracy for adults in full time employment in 13 countries.

A main finding was that data occupational complexity is strongly associated with numeracy, even when controlling for age, gender and education. The findings were obtained from an observational, cross-sectional survey, and must be interpreted accordingly. Assuming that the association has a causal component, there are both theoretical and practical implications. Theoretically the findings would strengthen the intellectual challenge hypothesis supporting claims that mechanisms of activity promote the maintenance and development of basic skills. Embracing alternative theoretical explanations for example explanations relating to learning theory, specifically situated learning, where learning is viewed as ongoing and supported through participation might better explain the findings and provide more direction for decision makers.

If there is a causal link from occupational complexity to numeracy, the findings would also inform policy-makers, labour organisations, and employers, as these these findings demonstrate the value of providing more challenging work tasks. Appropriate models of workplace organisation may serve to maintain and improve numeracy skills and thus realize the potential of workers, for their own benefit and for the benefit of society more generally.

\section{Appendices}

Appendix 1: Coding of complexity measures

See Tables 7, 8. 
Table 7 DOT complexity measures

\begin{tabular}{llllll}
\hline Complexity levels data & Value & Complexity levels people & Value & Complexity levels things & Value \\
\hline 0 Synthesizing & High & 0 Mentoring & High & 0 Setting up & High \\
1 Coordinating & High & 1 Negotiating & High & 1 Precision & High \\
2 Analysing & Mod. & 2 Instructing & High & 2 Operating & Mod. \\
3 Compiling & Mod. & 3 Supervising & Mod. & 3 Driving/manipulating & Mod. \\
4 Computing & Mod. & 4 Diverting & Mod. & 4 Tending & Low \\
5 Copying & Low & 5 Persuading & Mod. & 5 Feeding/off-bearing & Low \\
6 Comparing & Low & 6 Speaking/signalling & Low & 6 Handling & Low \\
& & 7 Serving & Low & & \\
& & 8Taking instructions & Low & & \\
\hline
\end{tabular}

Table 8 ISCO-08 codes and assigned levels of complexity with data, people and things

\begin{tabular}{|c|c|c|c|c|c|}
\hline 011-MHM & 223-MHM & 314-MLM & 431-MLL & 632-LLM & 816-LLM \\
\hline 021-MMM & 224-MMM & 315-MLH & 432-MLL & 633-LLM & 817-LLM \\
\hline 031-MLM & 225-HMH & 321-MLH & 441-MLL & 634-LLM & 818-LLM \\
\hline 111-HHL & 226- $\mathrm{HHH}$ & 322-MLM & 511-LLL & 711-MLM & 821-MLL \\
\hline 112-HHL & 231-HHL & 323-MHH & 512-LMM & 712-MLH & 831-LLM \\
\hline 121-HHL & 232-MHM & 324-LLM & 513-LLL & 713-LLM & 832-LLM \\
\hline $122-\mathrm{HHL}$ & 233-MHL & 325-MMM & 514-LLM & 721-MLH & 833-LLM \\
\hline 131-HML & 234-MHL & 331-MLL & 515-LHL & 722-MLH & 834-LLM \\
\hline 132-HML & 235-MHM & 332-MML & 516-LLM & 723-LLH & 835-LLM \\
\hline 133-HML & 241-MML & 333-MML & 521-MLM & 731-HLH & 911-LLL \\
\hline 134-HHL & 242-MML & 334-MLL & 522-LML & 732-LLH & 912-LLL \\
\hline 141-MML & 243-MHL & 335-MLL & 523-MLL & 741-MLH & 921-LLL \\
\hline 142-MML & 251-HLL & 341-MML & 524-LLL & 742-LLH & 931-LLL \\
\hline 143-MML & 252-HLL & 342-LHM & 531-HLL & 751-LLM & 932-LLL \\
\hline 211-HMH & 261-MML & 343-HLM & 532-LLL & 752-MLH & 933-LLL \\
\hline 212-HML & 262-MLL & 351-MLM & 541-LLM & 753-LLH & 941-LLL \\
\hline 213-HMH & 263-HML & 352-MLH & 611-MLM & 754-LLM & 951-LLL \\
\hline 214-HML & 264-MML & 411-MLL & 612-HMM & 811-LLH & 952-LLL \\
\hline 215-HMH & 265-LMM & 412-LLL & 613-HHM & 812-MLH & 961-LLL \\
\hline 216-HHH & 311-MLH & 413-MLL & 621-HHH & 813-LLM & 962-LLL \\
\hline 221-HHM & 312-MHL & 421-LLL & 622-MHH & 814-LLM & \\
\hline 222-MHM & 313-MMM & 422-MLL & 631-LLM & 815-LLM & \\
\hline
\end{tabular}

L, low; M, moderate; H, high. E.g., 214-HML means that ISCO code 214 corresponds to high data complexity, moderate people complexity and low things complexity

\section{Appendix 2: Occupational complexity}

Figure 6 shows the distribution of complexity levels within each complexity dimension for each country. One feature common to all countries is that for all three dimensions the smallest proportion of respondents, have occupations with a high level of complexity. This feature was found in the total data. Another feature common to all countries is that there are greater proportions coded with low complexity in the people and things dimensions than in the data dimension, suggesting labour markets where most jobs involve a moderate or high level of data management. There are variations across the countries, reflecting the composition of the individual labour markets. The 


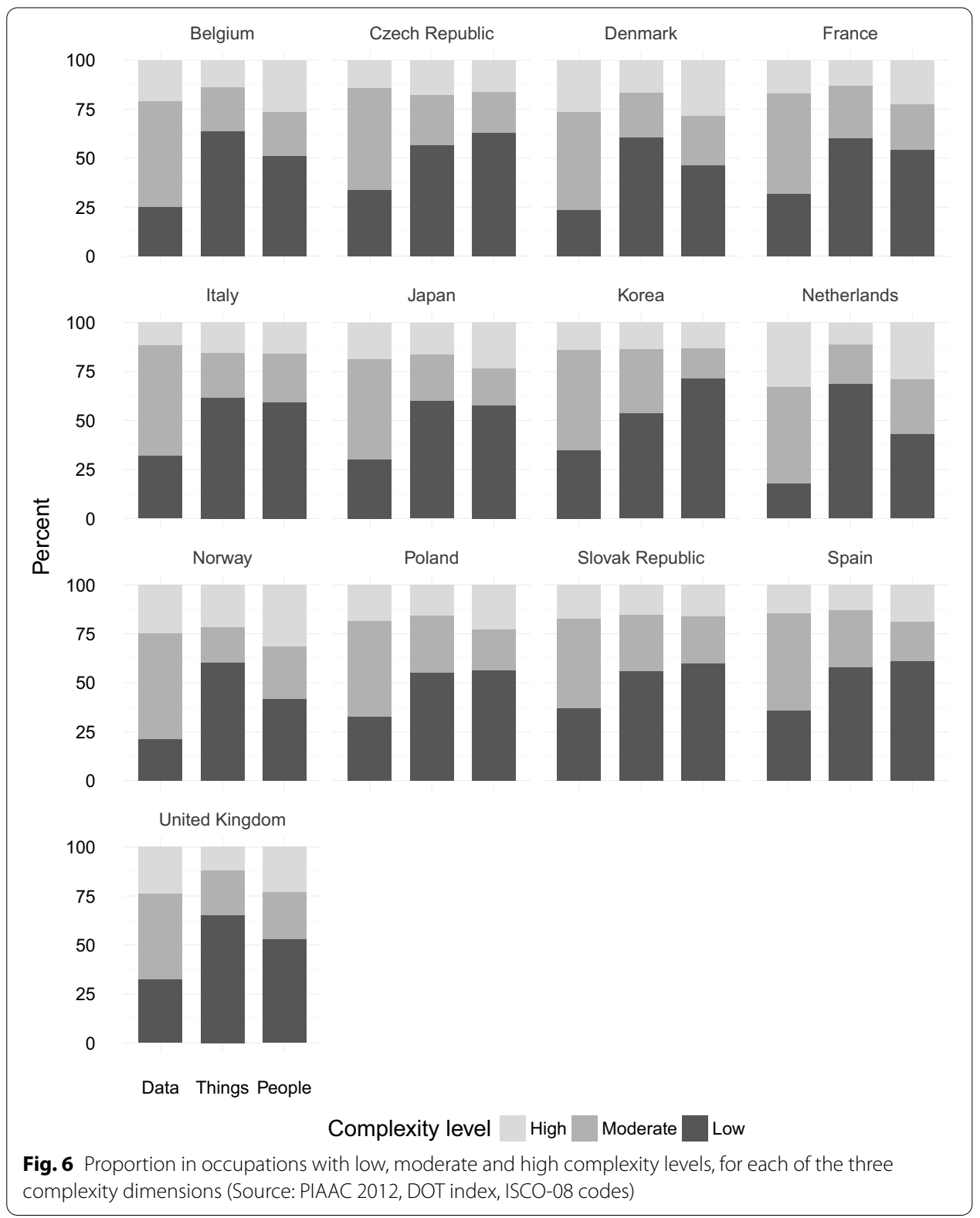

greatest variation is in the people dimension where the proportion of respondents with low complexity varied between from $40 \%$ in Norway to $70 \%$ in Korea.

General patterns of covariation appearing in the panels shown in Fig. 7 are as follows: (1) as the level of complexity with data increases, the proportions with moderate or high levels of complexity with people tend to increase (Panel 2a); (2) as the level of data complexity increases, the proportion with moderate or high level of things complexity decreases (Panel 2b); (3) with increasing levels of complexity with people, the proportions with moderate and high complexity with data increase (Panel 2c) ; (4) it is among the participants with the lowest level of people complexity that the proportion of high complexity with things is largest (Panel 2d); (5) a curvilinear relation, 


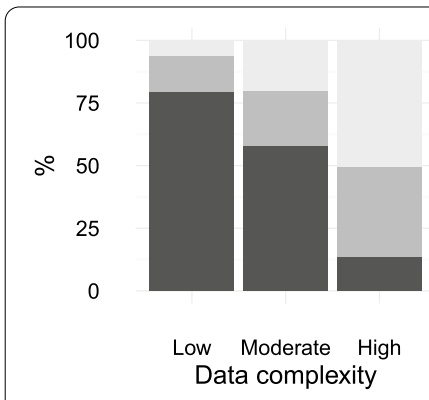

(a) Data vs People

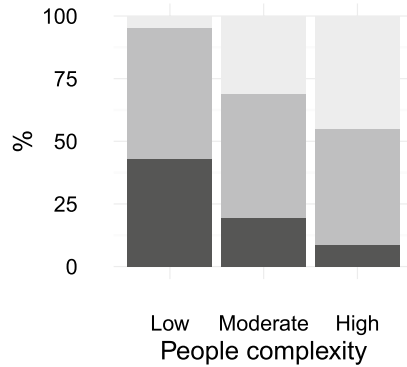

(c) People vs Data

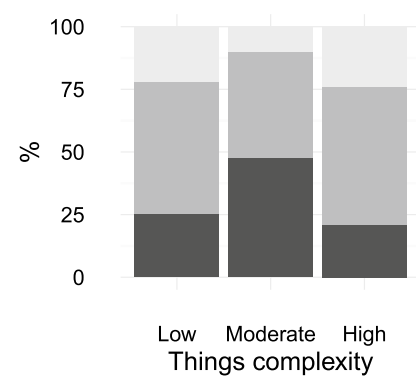

(e) Things vs Data

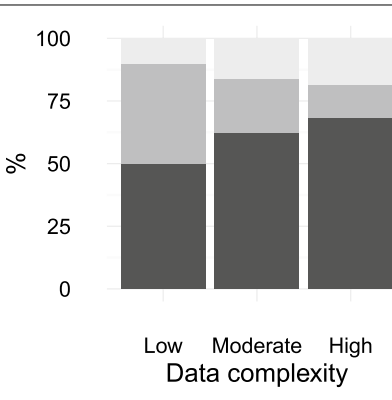

(b) Data vs Things

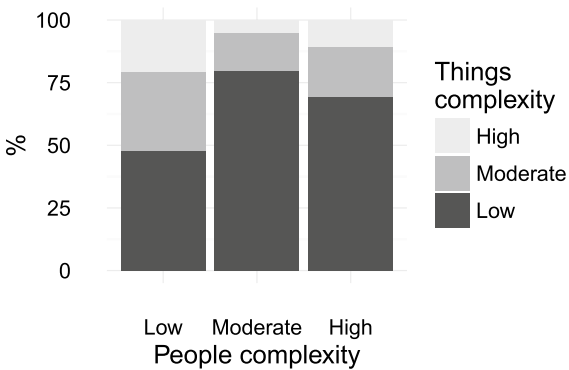

(d) People vs Things

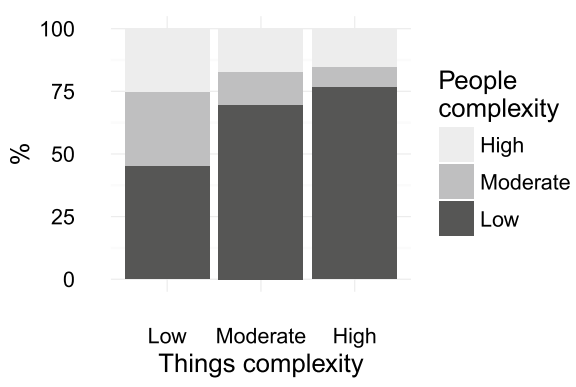

(f) Things vs People

Fig. 7 Relationship between pairs of occupational complexity dimensions. total data (Source: PIAAC 2012, DOT index, ISCO-08 codes)

with the lowest data complexity levels appearing among participants with moderate things complexity (Panel 2e); (6) that low complexity with things has the highest proportion of high complexity with people (Panel 2f).

\section{Appendix 3: Validity considerations}

The validity of our complexity construct may be gauged in different ways. Construct validity (Bryman, 2015; DeVellis, 2016) implies deducing a hypothesis from a theory that is relevant to the concept. The PIAAC data contains a number of self-reported variables. We chose to investigate the variables of job satisfaction and problem solving. We hypothesize that people with more complex and less routine jobs will be more 
Table 9 Job satisfaction at different levels of occupational complexity, total sample. Source: PIAAC 2012, DOT index, ISCO-08 codes

\begin{tabular}{llll}
\hline & \multicolumn{2}{l}{ Complexity type } & \\
\cline { 2 - 4 } & Data & People & Things \\
\hline High & 4.12 & 4.13 & 3.96 \\
Moderate & 4.00 & 4.06 & 3.92 \\
Low & 3.87 & 3.89 & 4.01 \\
\hline
\end{tabular}

Data occupational complexity with data, People Occupational complexity with people, Things Occupational complexity with things

Satisfaction was recoded with $1=$ Extremely dissatisfied; $2=$ Dissatisfied; $3=$ Neither satisfied nor dissatisfied; $4=$ Satisfied and $5=$ Extremely satisfied

Table 10 Mean of complex problem solving at work, at different levels of occupational complexity. Source: PIAAC 2012, DOT index, ISCO-08 codes

\begin{tabular}{lllc}
\hline & \multicolumn{2}{l}{ Complexity type } & Things \\
\cline { 2 - 4 } & Data & People & 3.08 \\
High & 3.51 & 3.26 & 2.64 \\
Moderate & 3.07 & 3.25 & 3.09 \\
Low & 2.47 & 2.75 & \\
\hline
\end{tabular}

Data occupational complexity with data, People Occupational complexity with people, Things Occupational complexity with things

Complex problem solving at work was recoded with $1=$ Never; $2=$ Less than once a month; $3=$ Less than once a week but at least once a month; $4=$ At least once a week but not every day and $5=$ Every day

satisfied with their jobs. We also hypothesize that people with more complex jobs will report higher frequencies of problem solving activities.

In the PIAAC interview, participants reported job satisfaction on a five-point Likert scale. Table 9 shows the calculated mean job satisfaction for individuals at each level and dimension of occupational complexity. Job satisfaction correlates positively with both the data and people dimensions of occupational complexity. However, there is no linear relationship between complexity with things and job satisfaction.

Similarly, in the PIAAC interview, respondents reported the frequency of encountering problems taking more than $30 \mathrm{~min}$ to solve, also on a five-point Likert scale. The findings in Table 10 show that higher levels of complexity with data and with people correlate positively with higher frequency of complex problem solving activities. Again, there is no linear relationship between complexity with things and the frequency of complex problem solving.

We conclude that the covariation with job satisfaction and frequency of complex problem solving activities lend validity to the constructed measures of data and people complexity. However, we found no such linear covariation for occupational complexity with things. In general, in our analysis the things dimension behaved differently to the other two dimensions. We take up this issue in the discussion.

\section{Appendix 4: Complete Regression Results per Country}

See Tables 11, 12, 13, 14, 15, 16, 17, 18, 19, 20, 21, 22, 23. 
Table 11 Regression results for Belgium. Source: PIAAC 2012, DOT index, ISCO-08 codes

\begin{tabular}{lcccc}
\hline & coef & se & t & p-val \\
\hline (Intercept) & $199.4^{* * *}$ & 6.9 & 29.0 & 0.000 \\
DatacomplexityModerate & $10.2^{* * *}$ & 2.8 & 3.6 & 0.000 \\
DatacomplexityHigh & $19.6^{* * *}$ & 3.2 & 6.1 & 0.000 \\
PeoplecomplexityModerate & 2.9 & 2.5 & 1.1 & 0.255 \\
PeoplecomplexityHigh & 0.1 & 2.6 & 0.0 & 0.963 \\
ThingscomplexityModerate & $-4.8^{*}$ & 2.6 & -1.9 & 0.068 \\
ThingscomplexityHigh & -3.3 & 3.3 & -1.0 & 0.314 \\
Female & $-15.3^{* * *}$ & 2.3 & -6.8 & 0.000 \\
Education years & $7.6^{* * *}$ & 0.5 & 16.0 & 0.000 \\
Age 35-44 & $-5.5^{* *}$ & 2.6 & -2.1 & 0.039 \\
Age 45-54 & $-9.8^{* * *}$ & 3.0 & -3.3 & 0.001 \\
Age 55 PLUS & $-23.3^{* * *}$ & 4.3 & -5.4 & 0.000 \\
\hline
\end{tabular}

$R^{2}=0.31$

$*{ }^{*},{ }^{* * * *}$ refer to significance at the $.1, .05$, and .01 levels, respectively

Table 12 Regression results for Czech Republic. Source: PIAAC 2012, DOT index, ISCO-08 codes

\begin{tabular}{lllll}
\hline & coef & se & t & p-val \\
\hline Intercept) & $191.2^{* * *}$ & 8.9 & 21.5 & 0.000 \\
DatacomplexityModerate & 1.8 & 2.8 & 0.6 & 0.520 \\
DatacomplexityHigh & 8 & 4.7 & 1.7 & 0.101 \\
PeoplecomplexityModerate & 1.3 & 3.4 & 0.4 & 0.698 \\
PeoplecomplexityHigh & -4 & 4.3 & -0.9 & 0.360 \\
ThingscomplexityModerate & -4 & 3.0 & -1.3 & 0.189 \\
ThingscomplexityHigh & -2.4 & 4.3 & -0.6 & 0.571 \\
Female & $-9.3^{* * *}$ & 3.2 & -3.0 & 0.004 \\
Education years & $7.5^{* * *}$ & 0.6 & 13.0 & 0.000 \\
Age 35-44 & $-7.8^{* * *}$ & 2.7 & -2.8 & 0.007 \\
Age 45-54 & $-10.2^{* * *}$ & 3.1 & -3.3 & 0.002 \\
Age 55 PLUS & $-16.2^{* * *}$ & 3.4 & -4.7 & 0.000 \\
\hline
\end{tabular}

$R^{2}=0.27$

*,**,**** refer to significance at the $.1, .05$, and .01 levels, respectively

Table 13 Regression results for Denmark. Source: PIAAC 2012, DOT index, ISCO-08 codes

\begin{tabular}{lcccc}
\hline & coef & se & t & p-val \\
\hline (Intercept) & $209.5^{* * *}$ & 5.9 & 35.6 & 0.000 \\
DatacomplexityModerate & $11.7^{* * *}$ & 2.1 & 5.7 & 0.000 \\
DatacomplexityHigh & $19.2^{* * *}$ & 3.0 & 6.3 & 0.000 \\
PeoplecomplexityModerate & -0.5 & 2.4 & -0.2 & 0.822 \\
PeoplecomplexityHigh & $-5^{* *}$ & 2.4 & -2.1 & 0.039 \\
ThingscomplexityModerate & $-5.5^{* *}$ & 2.1 & -2.5 & 0.014 \\
ThingscomplexityHigh & $-7.1^{* * *}$ & 2.3 & -3.1 & 0.003 \\
Female & $-15.6^{* * *}$ & 2.0 & -7.9 & 0.000 \\
Education years & $6.7^{* * *}$ & 0.4 & 16.9 & 0.000 \\
Age 35-44 & 0.2 & 2.7 & 0.1 & 0.943 \\
Age 45-54 & $-7.7^{* * *}$ & 2.6 & -3.0 & 0.004 \\
Age 55 PLUS & $-16.3^{* * *}$ & 2.7 & -6.1 & 0.000 \\
\hline
\end{tabular}

$R^{2}=0.27$

$* * * * * * *$ refer to significance at the $.1, .05$, and .01 levels, respectively 
Table 14 Regression results for France. Source: PIAAC 2012, DOT index, ISCO-08 codes

\begin{tabular}{lcccc}
\hline & coef & se & t & p-val \\
\hline (Intercept) & $184.3^{* * *}$ & 3.6 & 51.2 & 0.000 \\
DatacomplexityModerate & $12.1^{* * *}$ & 1.7 & 7.0 & 0.000 \\
DatacomplexityHigh & $20.4^{* * *}$ & 2.7 & 7.4 & 0.000 \\
PeoplecomplexityModerate & $4.2^{*}$ & 2.2 & 2.0 & 0.054 \\
PeoplecomplexityHigh & 1.4 & 1.9 & 0.7 & 0.476 \\
ThingscomplexityModerate & $-4.3^{* *}$ & 1.8 & -2.3 & 0.024 \\
ThingscomplexityHigh & -0.6 & 2.4 & -0.2 & 0.809 \\
Female & $-9.7^{* * *}$ & 1.7 & -5.6 & 0.000 \\
Education years & $7.1^{* * *}$ & 0.3 & 27.2 & 0.000 \\
Age 35-44 & -3.1 & 1.9 & -1.6 & 0.110 \\
Age 45-54 & $-12.6^{* * *}$ & 2.4 & -5.3 & 0.000 \\
Age 55 PLUS & $-17.3^{* * *}$ & 2.6 & -6.5 & 0.000 \\
\hline
\end{tabular}

$R^{2}=0.37$

$*{ }^{*},{ }^{* * * *}$ refer to significance at the $.1, .05$, and .01 levels, respectively

Table 15 Regression results for Italy. Source: PIAAC 2012, DOT index, ISCO-08 codes

\begin{tabular}{lcccc}
\hline & coef & se & t & p-val \\
\hline Intercept) & $211.4^{* * *}$ & 7.1 & 29.9 & 0.000 \\
DatacomplexityModerate & $5.7^{*}$ & 3.2 & 1.8 & 0.078 \\
DatacomplexityHigh & $14^{* * *}$ & 5.0 & 2.8 & 0.006 \\
PeoplecomplexityModerate & 3.5 & 3.8 & 0.9 & 0.365 \\
PeoplecomplexityHigh & $-11^{* *}$ & 4.6 & -2.4 & 0.020 \\
ThingscomplexityModerate & $-8^{* *}$ & 3.7 & -2.2 & 0.035 \\
ThingscomplexityHigh & -0.3 & 4.3 & -0.1 & 0.936 \\
Female & $-11.1^{* * *}$ & 2.5 & -4.5 & 0.000 \\
Education years & $4.9^{* * *}$ & 0.4 & 11.8 & 0.000 \\
Age 35-44 & -4.1 & 3.6 & -1.1 & 0.257 \\
Age 45-54 & -4.5 & 3.6 & -1.2 & 0.222 \\
Age 55 PLUS & $-16.4^{* * *}$ & 5.3 & -3.1 & 0.003 \\
\hline
\end{tabular}

$R^{2}=0.23$

$*^{*}, * *, * * *$ refer to significance at the $.1, .05$, and .01 levels, respectively

Table 16 Regression results for Japan. Source: PIAAC 2012, DOT index, ISCO-08 codes

\begin{tabular}{lcccc}
\hline & coef & se & t & p-val \\
\hline (Intercept) & $209.8^{* * *}$ & 5.7 & 37.0 & 0.000 \\
DatacomplexityModerate & $6.7^{* * *}$ & 2.0 & 3.3 & 0.001 \\
DatacomplexityHigh & $12.9^{* * *}$ & 3.4 & 3.8 & 0.000 \\
PeoplecomplexityModerate & -2.4 & 2.3 & -1.0 & 0.299 \\
PeoplecomplexityHigh & -1.1 & 2.4 & -0.5 & 0.643 \\
ThingscomplexityModerate & $-7^{* * *}$ & 2.4 & -2.9 & 0.006 \\
ThingscomplexityHigh & $-4.8^{*}$ & 2.4 & -2.0 & 0.052 \\
Female & $-8.3^{* * *}$ & 2.0 & -4.1 & 0.000 \\
Education years & $6.8^{* * *}$ & 0.4 & 18.9 & 0.000 \\
Age 35-44 & 0.8 & 2.3 & 0.3 & 0.732 \\
Age 45-54 & -4.7 & 2.9 & -1.7 & 0.103 \\
Age 55 PLUS & $-14.3^{* * *}$ & 3.1 & -4.6 & 0.000 \\
\hline
\end{tabular}

$R^{2}=0.25$

$* * * * * * *$ refer to significance at the $.1, .05$, and .01 levels, respectively 
Table 17 Regression results for Korea. Source: PIAAC 2012, DOT index, ISCO-08 codes

\begin{tabular}{lcccc}
\hline & coef & se & t & p-val \\
\hline (Intercept) & $193.2^{* * *}$ & 4.8 & 40.4 & 0.000 \\
DatacomplexityModerate & $4.3^{* * *}$ & 1.5 & 2.8 & 0.007 \\
DatacomplexityHigh & $7.7^{* * *}$ & 2.6 & 2.9 & 0.004 \\
PeoplecomplexityModerate & 3.5 & 2.3 & 1.5 & 0.132 \\
PeoplecomplexityHigh & $4.7^{*}$ & 2.6 & 1.8 & 0.074 \\
ThingscomplexityModerate & $-2.9^{*}$ & 1.7 & -1.8 & 0.084 \\
ThingscomplexityHigh & -3.2 & 2.6 & -1.2 & 0.224 \\
Female & $-7.9^{* * *}$ & 1.6 & -5.1 & 0.000 \\
Education years & $6^{* * *}$ & 0.3 & 19.7 & 0.000 \\
Age 35-44 & -2.6 & 2.3 & -1.2 & 0.246 \\
Age 45-54 & $-13.1^{* * *}$ & 2.5 & -5.3 & 0.000 \\
Age 55 PLUS & $-17.8^{* * *}$ & 3.1 & -5.7 & 0.000 \\
\hline
\end{tabular}

$R^{2}=0.34$

$*{ }^{*},{ }^{* * * *}$ refer to significance at the $.1, .05$, and .01 levels, respectively

Table 18 Regression results for Netherlands. Source: PIAAC 2012, DOT index, ISCO-08 codes

\begin{tabular}{lllll}
\hline & coef & se & t & p-val \\
\hline Intercept) & $187.9^{* * *}$ & 6.8 & 27.5 & 0.000 \\
DatacomplexityModerate & $12.5^{* * *}$ & 3.1 & 4.1 & 0.000 \\
DatacomplexityHigh & $18.2^{* * *}$ & 3.6 & 5.0 & 0.000 \\
PeoplecomplexityModerate & 0.5 & 2.8 & 0.2 & 0.854 \\
PeoplecomplexityHigh & -0.4 & 2.8 & -0.2 & 0.876 \\
ThingscomplexityModerate & $-6^{* *}$ & 2.8 & -2.1 & 0.041 \\
ThingscomplexityHigh & -3.6 & 3.6 & -1.0 & 0.324 \\
Female & $-16.2^{* * *}$ & 2.8 & -5.8 & 0.000 \\
Education years & $7.7^{* * *}$ & 0.5 & 16.1 & 0.000 \\
Age 35-44 & -2 & 2.7 & -0.7 & 0.466 \\
Age 45-54 & $-7.6^{* * *}$ & 2.7 & -2.9 & 0.005 \\
Age 55 PLUS & $-18.4^{* * *}$ & 3.2 & -5.8 & 0.000 \\
\hline
\end{tabular}

$R^{2}=0.31$

${ }^{*},{ }^{* *},{ }^{* * *}$ refer to significance at the $.1, .05$, and .01 levels, respectively

Table 19 Regression results for Norway. Source: PIAAC 2012, DOT index, ISCO-08 codes

\begin{tabular}{lcccc}
\hline & coef & se & t & p-val \\
\hline (Intercept) & $191.6^{* * *}$ & 7.7 & 24.9 & 0.000 \\
DatacomplexityModerate & $16.4^{* * *}$ & 2.4 & 6.7 & 0.000 \\
DatacomplexityHigh & $20.4^{* * *}$ & 3.0 & 6.7 & 0.000 \\
PeoplecomplexityModerate & $8.7^{* * *}$ & 3.0 & 2.9 & 0.005 \\
PeoplecomplexityHigh & 0.3 & 3.0 & 0.1 & 0.910 \\
ThingscomplexityModerate & -1.4 & 2.7 & -0.5 & 0.598 \\
ThingscomplexityHigh & $7.1^{* *}$ & 3.0 & 2.4 & 0.021 \\
Female & $-14.6^{* * *}$ & 2.1 & -7.0 & 0.000 \\
Education years & $6.8^{* * *}$ & 0.5 & 14.0 & 0.000 \\
Age 35-44 & -1.3 & 3.1 & -0.4 & 0.684 \\
Age 45-54 & $-8.8^{* * *}$ & 2.7 & -3.2 & 0.002 \\
Age 55 PLUS & $-21.5^{* * *}$ & 3.5 & -6.2 & 0.000 \\
\hline
\end{tabular}

$R^{2}=0.29$

$* * * * * * *$ refer to significance at the $.1, .05$, and .01 levels, respectively 
Table 20 Regression results for Poland. Source: PIAAC 2012, DOT index, ISCO-08 codes

\begin{tabular}{lcccc}
\hline & coef & se & t & p-val \\
\hline (Intercept) & $183.2^{* * *}$ & 6.5 & 28.3 & 0.000 \\
DatacomplexityModerate & $6.4^{* *}$ & 2.7 & 2.3 & 0.022 \\
DatacomplexityHigh & 5.7 & 3.7 & 1.6 & 0.122 \\
PeoplecomplexityModerate & 2.9 & 3.3 & 0.9 & 0.379 \\
PeoplecomplexityHigh & 1.3 & 2.9 & 0.5 & 0.652 \\
ThingscomplexityModerate & $-10.3^{* * *}$ & 2.8 & -3.7 & 0.000 \\
ThingscomplexityHigh & -2.8 & 3.3 & -0.9 & 0.392 \\
Female & $-11.5^{* * *}$ & 2.3 & -4.9 & 0.000 \\
Education years & $6.7^{* * *}$ & 0.4 & 15.1 & 0.000 \\
Age 35-44 & -2.1 & 2.3 & -0.9 & 0.368 \\
Age 45-54 & -3.6 & 3.0 & -1.2 & 0.233 \\
Age 55 PLUS & -3.3 & 4.2 & -0.8 & 0.432 \\
\hline
\end{tabular}

$R^{2}=0.22$

${ }^{*}, * *,{ }^{* * *}$ refer to significance at the $.1, .05$, and .01 levels, respectively

Table 21 Regression results for Slovak Republic. Source: PIAAC 2012, DOT index, ISCO-08 codes

\begin{tabular}{lcccc}
\hline & coef & se & t & p-val \\
\hline (Intercept) & $208.5^{* * *}$ & 6.6 & 31.7 & 0.000 \\
DatacomplexityModerate & 2.9 & 2.8 & 1.1 & 0.296 \\
DatacomplexityHigh & 6.2 & 3.7 & 1.7 & 0.101 \\
PeoplecomplexityModerate & 2 & 2.2 & 0.9 & 0.361 \\
PeoplecomplexityHigh & -1.9 & 2.7 & -0.7 & 0.477 \\
ThingscomplexityModerate & $-4.2^{*}$ & 2.4 & -1.8 & 0.084 \\
ThingscomplexityHigh & -0.3 & 3.4 & -0.1 & 0.939 \\
Female & $-3.9^{*}$ & 2.1 & -1.9 & 0.066 \\
Education years & $5.7^{* * *}$ & 0.5 & 11.5 & 0.000 \\
Age 35-44 & 2.4 & 2.5 & 1.0 & 0.346 \\
Age 45-54 & -0.5 & 2.2 & -0.2 & 0.811 \\
Age 55 PLUS & $-8.1^{* *}$ & 3.2 & -2.5 & 0.017 \\
\hline
\end{tabular}

$R^{2}=0.17$

$* * * * * * *$ refer to significance at the $.1, .05$, and .01 levels, respectively

Table 22 Regression results for Spain Source: PIAAC 2012, DOT index, ISCO-08 codes

\begin{tabular}{lccll}
\hline & coef & se & t & p-val \\
\hline (Intercept) & $197.6^{* * *}$ & 4.7 & 42.1 & 0.000 \\
DatacomplexityModerate & $8.1^{* * *}$ & 2.5 & 3.2 & 0.002 \\
DatacomplexityHigh & $13.4^{* * *}$ & 4.0 & 3.4 & 0.001 \\
PeoplecomplexityModerate & 1.7 & 2.5 & 0.7 & 0.493 \\
PeoplecomplexityHigh & 0.6 & 2.7 & 0.2 & 0.838 \\
ThingscomplexityModerate & $-5.9^{* * *}$ & 2.1 & -2.7 & 0.008 \\
ThingscomplexityHigh & 2.2 & 2.5 & 0.9 & 0.378 \\
Female & $-18.1^{* * *}$ & 2.0 & -8.9 & 0.000 \\
Education years & $5.7^{* * *}$ & 0.3 & 19.7 & 0.000 \\
Age 35-44 & 1.3 & 2.1 & 0.6 & 0.547 \\
Age 45-54 & $-6.4^{* * *}$ & 2.4 & -2.7 & 0.007 \\
Age 55 PLUS & $-18.6^{* * *}$ & 3.3 & -5.6 & 0.000 \\
\hline
\end{tabular}

$R^{2}=0.33$

$* * * * * * *$ refer to significance at the $.1, .05$, and .01 levels, respectively 
Table 23 Regression results for United Kingdom. Source: PIAAC 2012, DOT index, ISCO-08 codes

\begin{tabular}{lcccc}
\hline & coef & se & t & p-val \\
\hline (Intercept) & $197.7^{* * *}$ & 9.2 & 21.6 & 0.000 \\
DatacomplexityModerate & $16.7^{* * *}$ & 3.2 & 5.3 & 0.000 \\
DatacomplexityHigh & $24.5^{* * *}$ & 4.3 & 5.7 & 0.000 \\
PeoplecomplexityModerate & 2.7 & 3.6 & 0.7 & 0.457 \\
PeoplecomplexityHigh & 2.6 & 3.5 & 0.7 & 0.461 \\
ThingscomplexityModerate & -3.8 & 3.1 & -1.2 & 0.229 \\
ThingscomplexityHigh & 5.4 & 3.7 & 1.5 & 0.144 \\
Female & $-13.9^{* * *}$ & 2.8 & -5.1 & 0.000 \\
Education years & $5.8^{* * *}$ & 0.7 & 8.7 & 0.000 \\
Age 35-44 & 0.6 & 3.5 & 0.2 & 0.865 \\
Age 45-54 & $-7.5^{* *}$ & 3.4 & -2.2 & 0.032 \\
Age 55 PLUS & $-9.5^{* *}$ & 4.4 & -2.2 & 0.040 \\
\hline$R^{2}=0.2$ & & & &
\end{tabular}

$R^{2}=0.2$

${ }^{*},{ }^{* *},{ }^{* * *}$ refer to significance at the $.1, .05$, and .01 levels, respectively

\section{Acknowledgements}

None.

\section{Authors' contributions}

Billington conceived the coding of occupational complexity through combining ISCO codes with the DOT handbook, and was responsible for the coding procedure. Foldnes responsible for data analysis and produced all tables and figures. Authors co-wrote the introduction and discussion. Both authors read and approved the final manuscript.

\section{Funding}

This study was funded by Norges Forskningsråd (Grant Number 228298).

Availability of data and materials

PIAAC data are publicly available. $\mathrm{R}$ code available upon request to corresponding author.

\section{Declarations}

Ethics approval and consent to participate

Not applicable (we use only PIAAC data).

\section{Consent for publication}

Not applicable.

\section{Competing interests}

The authors declare that there is no competing interests.

Received: 22 March 2021 Accepted: 20 August 2021

Published online: 01 September 2021

\section{References}

Andel, R., Crowe, M., Pedersen, N. L., Mortimer, J., Crimmins, E., Johansson, B., \& Gatz, M. (2005). Complexity of work and risk of alzheimer's disease: A population-based study of swedish twins. The Journals of Gerontology Series B: Psychological Sciences and Social Sciences, 60(5), P251-P258.

Andel, R., Ross, A., Merril, S., \& Ingemar, K. (2014). The role of midlife occupational complexity and leisure activity in LateLife cognition. Journals of Gerontology Series B: Psychological Sciences and Social Sciences, 70(2), 314-321.

Bailey, P., Emad, A., Huo, H., Lee, M., Liao, Y., Lishinski, A., \& Christensen, A. A. (2021). Edsurvey: Analysis of nces education survey and assessment data [Computer software manual]. (R package version 2.6.9).

Bailey, P., Lee, M., Nguyen, T., \& Zhang, T. (2020). Using edsurvey to analyse PIAAC data. Large-scale cognitive assessment (pp. 209-237). Springer.

Baldivia, B., Andrade, V. M., \& Bueno, O. F. A. (2008). Contribution of education, occupation and cognitively stimulating activities to the formation of cognitive reserve. Dementia \& Neuropsychologia, 2(3), 173.

Becker, G. S. (2009). Human capital: A theoretical and empirical analysis, with special reference to education. University of Chicago press.

Bennison, A. (2015). Developing an analytic lens for investigating identity as an embedder-of-numeracy. Mathematics Education Research Journal, 27(1), 1-19. 
Billington, M. G., Nissinen, K., \& Gabrielsen, E. (2017). When investment in basic skills gives negative returns. Adult Education Quarterly, 67(2), 136-154.

Bryman, A. (2015). Social research methods. Oxford University Press.

Burns, T., Fitzpatick, M., \& Lavinson, R. (2016). Trends shaping education 2016. OECD Publishing.

Cascio, E., Clark, D., \& Gordon, N. (2008). Education and the age profile of literacy into adulthood. Journal of Economic Perspectives, 22(3), 47-70.

Clair, R. S. (2012). The limits of levels: Understanding the international adult literacy surveys (ials). International Review of Education, 58(6), 759-776.

Cohen, J. (1988). Statistical power analysis for the behavioural sciences. Lawrence Earlbaum Associates.

Coulombe, S., \& Tremblay, J.-F. (2009). Migration and skills disparities across the Canadian provinces. Regional Studies, 43(1), 5-18.

de Grip, A., Bosma, H., Willems, D., \& van Boxtel, M. (2007). Job-worker mismatch and cognitive decline. Oxford Economic Papers, 60(2), 237-253.

Della Torre, E., Zatzick, C. D., Sikora, D., \& Solari, L. (2018). Workforce churning, human capital disruption, and organisational performance in different technological contexts. Human Resource Management Journal, 28(1), 112-127.

Desjardins, R. (2003). Determinants of literacy proficiency: A lifelong-lifewide learning perspective. International Journal of Educational Research, 39(3), 205-245.

Desjardins, R., \& Rubenson, K. (2013). Participation patterns in adult education: The role of institutions and public policy frameworks in resolving coordination problems. European Journal of Education, 48(2), 262-280.

Desjardins, R., Thorn, W., Schleicher, A., Quintini, G., Pellizzari, M., Kis, V., \& Chung, J. E. (2013). OECD skills outlook 2013: First results from the survey of adult skills. Journal of Applied Econometrics, 30(7), 1144-1168.

DeVellis, R. F. (2016). Scale development: Theory and applications (Vol. 26). Sage publications.

Dictionary of occupational titles. (2016). Retrieved December 18, 2016 from www.occupationalinfo.org.

Edin, P.-A., \& Gustavsson, M. (2008). Time out of work and skill depreciation. ILR Review, 61(2), 163-180.

England, P., \& Kilbourne, B. (1988). Occupational measures from the dictionary of occupational titles for 1980 census detailed occupations (Vol. 8942). Inter-university Consortium for Political and Social Research.

Evans, K., Waite, E., \& Kersh, N. (2011). Towards a social ecology of adult learning in and through the workplace. The SAGE handbook of workplace learning, pp. 456-465.

Feldberg, C., Carolina, F., Dorina, S., \& Ricardo, A. (2014). Occupational complexity and leisure activities in cognitive aging. Current Psychopharmacology, 3(1), 50-58.

Finkel, D., Deborah, F., Ross, A., Margaret, G., \& Pedersen, N. L. (2009). The role of occupational complexity in trajectories of cognitive aging before and after retirement. Psychology Aging, 24(3), 563-573.

Foldnes, N., \& Grønneberg, S. (2020). Pernicious polychorics: The impact and detection of underlying non-normality. Structural Equation Modeling: A Multidisciplinary Journal, 27(4), 525-543.

Fujishiro, K., MacDonald, L. A., Crowe, M., McClure, L. A., Howard, V. J., \& Wadley, V. G. (2019). The role of occupation in explaining cognitive functioning in later life: Education and occupational complexity in a us national sample of black and white men and women. The Journals of Gerontology: Series B, 74(7), 1189-1199.

Garcia-Retamero, R., Andrade, A., Sharit, J., \& Ruiz, J. G. (2015). Is patients' numeracy related to physical and mental health? Medical Decision Making, 35(4), 501-511.

Geiger, V., Forgasz, H., \& Goos, M. (2015). A critical orientation to numeracy across the curriculum. ZDM, 47(4), 611-624.

Greenberg, D. (2013). Adult literacy: The state of the field. Perspectives on Language and Literacy, 39(2), 9.

Greene, D. R. (2013). Relationship between occupational complexity and dementia risk in late life: A population study (Doctoral dissertation. Utah State University).

Hanushek, E. A., \& Zhang, L. (2006). Quality-consistent estimates of international returns to skill. (NBER Working Paper No. 12664). National Bureau of Economic Research. http://www.nber.org/papers/w12664.

International standard classification of occupations. (2010). Isco-08.http://www.who.int/hrh/resources/observer4/en/ index.html.

Jenks, S. (1992). Researchers link low literacy to high health care costs. JNCI Journal of the National Cancer Institute, 84(14), 1068-1069.

Kwon, D.-B. (2009). Human capital and its measurement. In: The 3rd OECD world forum on "statistics, knowledge and policy" charting progress, building visions, improving life (pp. 27-30).

Marquié, J.-C., Duarte, L. R., Bessières, P., Dalm, C., Gentil, C., \& Ruidavets, J. (2010). Higher mental stimulation at work is associated with improved cognitive functioning in both young and older workers. Ergonomics, 53(11), 1287-1301.

McIntosh, S., \& Vignoles, A. (2001). Measuring and assessing the impact of basic skills on labour market outcomes. Oxford Economic Papers, 53(3), 453-481.

OECD. (2013a). OECD skills outlook 2013: First results from the survey of adult skills. OECD Publishing Paris.

OECD. (2013b). Technical report of the survey of adult skills (PIAAC). OECD Publishing Paris.

Parsons, S., \& Bynner, J. (1997). Numeracy and employment. Education Training, 39(2), $43-51$.

Parsons, S., \& Bynner, J. (1999). Lack of employment: The threat to numeracy. Education Training, 41(8), 359-366.

Parsons, S., \& Bynner, J. (2005). Does numeracy matter more? National Research and Development Centre for adult literacy and numeracy.

Potter, G. G., Helms, M. J., \& Plassman, B. L. (2007). Associations of job demands and intelligence with cognitive performance among men in late life. Neurology, 70(Issue 19, Part 2), 1803-1808.

R Core Team. (2020). R: A language and environment for statistical computing [Computer software manual]. Vienna: Austria. Retrieved from https://www.R-project.org/.

Reder, S., \& Bynner, J. (2008). Tracking adult literacy and numeracy skills: Findings from longitudinal research. Routledge.

Reder, S., Gauly, B., \& Lechner, C. (2020). Practice makes perfect: Practice engagement theory and the development of adult literacy and numeracy proficiency. International Review of Education, 66(2), 267-288.

Schleicher, A. (2008). PIAAC: A new strategy for assessing adult competencies. International Review of Education, 54(5-6), $627-650$. 
Smart, E. L., Gow, A. J., \& Deary, I. J. (2014). Occupational complexity and lifetime cognitive abilities. Neurology, 83(24), 2285-2291.

Staff, R. T., Murray, A. D., Deary, I. J., \& Whalley, L. J. (2004). What provides cerebral reserve? Brain, 127(5), 1191-1199.

Tighe, E. L., Barnes, A. E., Connor, C. M., \& Steadman, S. C. (2013). Defining success in adult basic education settings: Multiple stakeholders, multiple perspectives. Reading Research Quarterly, 48(4), 415-435.

Tout, D. (2014). Don't subtract numeracy. In Research developments, ACER. Retrieved from http://rd.acer.edu.au/article/ dont-subtract-numeracy.

Valdés, E. G., Andel, R., Sieurin, J., Feldman, A. L., Edwards, J. D., Långström, N., \& Wirdefeldt, K. (2014). Occupational complexity and risk of Parkinson's disease. PLoS ONE, 9(9), e106676.

Vignoles, A., De Coulon, A., \& Marcenaro-Gutierrez, O. (2011). The value of basic skills in the British labour market. Oxford Economic Papers, 63(1), 27-48.

Willms, J. D., \& Murray, T. S. (2007). Gaining and losing literacy skills over the lifecourse. Statistics Canada.

\section{Publisher's Note}

Springer Nature remains neutral with regard to jurisdictional claims in published maps and institutional affiliations.

\section{Submit your manuscript to a SpringerOpen ${ }^{0}$} journal and benefit from:

- Convenient online submission

- Rigorous peer review

- Open access: articles freely available online

- High visibility within the field

- Retaining the copyright to your article

Submit your next manuscript at $\boldsymbol{\Delta}$ springeropen.com 